STATEMENT OF INTEREST

None declared.

\section{REFERENCES}

1 Fabbri LM, Luppi F, Benghè B, Rabe K. Complex chronic comorbidities of COPD. Eur Respir J 2008; 31: 204-212.

2 Italian Health Department. Guidelines on osteoporosis. www.ministerosalute.it/alimenti/nutrizione/linee.jsp?lang= italiano\&label $=$ oste\&id $=83$ Date last updated and accessed: July 3, 2008.

3 Consensus Development Conference. Diagnosis, prophylaxis, and treatment of osteoporosis. Am J Med 1993; 94: 646-650.
4 Consensus Development Statement. Who are candidates for prevention and treatment for osteoporosis? Osteop Int 1997; 7: $1-6$.

5 Osteoporosis prevention, diagnosis, and therapy. NIH Consensus Statement 2000; 17: 1-45.

6 Italian Society for Osteoporosis and Mineral Metabolism and Bone Disease (SIOMMMS). Guidelines for diagnosis, prevention and therapy of osteoporosis. Edn EDIMES, Pavia, 2006.

7 The Medical Letter, Italian Edition 2008:1;1.

8 Hubbard R, Tattersfield A, Smith C, West J, Smeeth L, Fletcher A. Use of inhaled corticosteroids and the risk of fracture. Chest 2006; 130: 1082-1088.

DOI: $10.1183 / 09031936.00034608$

\title{
Doubts about the role of cannabis in causing lung
}

\section{cancer}

\section{To the Editors:}

We read with interest the article by ALDINGTON et al. [1] entitled "Cannabis use and risk of lung cancer: a case-control study". However, we are concerned that the conclusion stating that "long-term cannabis use increases the risk of lung cancer in young adults" is inadequately supported by the data, given the study's several methodological flaws.

First, ALDINGTON et al. [1] argue that the risk of lung cancer increases linearly by $8 \%$ per pack-yr smoked, based on the assumption that cancer risk from cannabis smoking is similar to cancer risk from tobacco smoking, which also increases linearly with pack-yrs. However, their own data show that the cancer risk from tobacco smoking does not increase linearly, but rather geometrically, rendering the assumption invalid. Furthermore, the authors found an increased risk of lung cancer only in the highest tertile of cannabis smokers, rendering the posited linear relationship inappropriate.

Secondly, since over half of the subjects were $>50$ yrs of age, it seems misleading to refer to them as "young adults".

Thirdly, although the study is powered at $80 \%$ to detect an odds ratio (OR) of 2.4 for lung cancer in the $15 \%$ of the population who smoke cannabis, it is only the considerably smaller population that had smoked $>10.5$ joint-yrs that showed an increased risk. Epidemiological data on the percentage of the population that has smoked $>10.5$ joint-yrs are not available, but if the sample provided by ALDINGTON et al. [1] is representative, the figure is only $4.5 \%$. Therefore, the study is underpowered at $25 \%$ for an OR of 2.4 and $31 \%$ for an OR of 2.7. A sample of 12,000 cases and 50,000 controls would be required to detect, at $80 \%$ power, a relative risk of 1.08 per joint-yr reported by the authors. Consequently, their conclusion is probably only a chance finding.

Fourthly, although the study is termed "case-control", the cases are adequately matched with controls only for sex. Subjects in the case group were disproportionate in age, education, wealth, heritage and smoking history; all of which are independent risk factors for lung cancer.

With that in mind, ALDINGTON et al. [1] dismissal of a much larger study of 2,252 subjects by HASHIBE et al. [2] in 2006, which found no increase in cancer risk, even in those patients who smoked $>60$ joint-yrs on the grounds that controls were matched for neighbourhood is puzzling, because controls should be matched for neighbourhood.

Finally, an observational study such as ALDINGTON et al. [1] cannot establish causality, only correlation. Even presupposing that the study was methodologically impeccable, the strongest conclusion that could be drawn would be that "long-term cannabis use is associated with an increased risk of lung cancer", not that cannabis use causes lung cancer.

Given the acrimonious debate over the role of cannabis in society, and the substantial chance that this paper will contribute to public policy decisions, we feel it is important to keep conclusions that are stated in abstracts and papers as close to the actual scientific findings as possible.

\section{R.A. Sewell*\#, A.J. Cohn ${ }^{\Uparrow}$ and M.C. Chawarski ${ }^{\#}$}

*VA Connecticut Healthcare, West Haven, "Yale University School of Medicine, New Haven, CT, and "Advisory Committee on Medical Marijuana, Portland, OR, USA. 


\section{STATEMENT OF INTEREST}

None declared.

\section{REFERENCES}

1 Aldington S, Harwood M, Cox B, et al. Cannabis use and risk of lung cancer: a case-control study. Eur Respir J 2008; 31: 280-286.
2 Hashibe M, Morgenstern H, Cui Y, et al. Marijuana use and the risk of lung and upper aerodigestive tract cancers: results of a population-based case-control study. Cancer Epidemiol Biomarkers Prev 2006; 15: 1829-1834.

\section{Noninvasive ventilation and the potential risk of transmission of infection}

\section{To the Editors:}

In their exhaustive review on noninvasive ventilation (NIV) in acute respiratory failure, AMBROSINO and VAGHEGGINI [1] do not mention the potential risk of transmitting infections during its application.

Noninvasive positive-pressure ventilation (NPPV) is becoming increasingly used in patients with acute respiratory failure caused by a wide range of infectious aetiologies such as human-adapted avian influenza, aspergillosis and varicella [2-4], in order to avoid intubation or as a bridge to invasive mechanical ventilation. Substantial exposure to exhaled air occurs within a $0.5-\mathrm{m}$ radius of patients receiving NPPV at usual pressures (expiratory positive airway pressure $45 \mathrm{cmH}_{2} \mathrm{O}(0.39 \mathrm{kPa})$; inspiratory positive airway pressure $\left.1,215 \mathrm{cmH}_{2} \mathrm{O}(1.18 \mathrm{kPa})\right)$ : higher ventilator pressures result in a wider distribution of exhaled air [5]. Indeed, in the recently proposed World Health Organization interim guidelines on prevention and control of acute respiratory diseases in healthcare, NIV has been included among those aerosol-generating procedures in which the risk of pathogen transmission is still "controversial/possible" but not documented [6].

Furthermore, reusable equipment used in delivering NPPV may be exposed to potentially infectious material during routine use through contact with the patient's skin, mucousal membranes, respiratory secretions and blood. If this reusable equipment is not properly disinfected between patients it can lead to a major nosocomial transmission of a wide range of respiratory pathogens.

Reusable masks and exhalation valves should be disassembled into their component parts before undergoing an automated process utilising a combined washer/disinfector/drier that uses heat at a moderate but effective temperature; e.g. the Health Technical memorandum HTM2030 cycle which peaks at $87^{\circ} \mathrm{C}$ for $1 \mathrm{~min}$. Reusable tubing is difficult to decontaminate effectively using this method (because of the length and diameter of the lumen); however, it can be autoclaved at $134^{\circ} \mathrm{C}$ for $3.5 \mathrm{~min}$. Headgear and chinstraps should be treated in a washing machine with a cycle that reaches either $65^{\circ} \mathrm{C}$ for $10 \mathrm{~min}$ or $71^{\circ} \mathrm{C}$ for $3 \mathrm{~min}$. In most ventilators used for NIV there is no airflow from the patient back into the ventilator.
Hence, the risk of contamination of the ventilator is extremely low providing a bacterial filter is used and superficial cleaning of the ventilator between patients is satisfactory.

Healthcare workers should be aware of the potential risks of infection transmission during noninvasive positive-pressure ventilation, and should take stringent contact and droplet precaution.

\section{A. Singh* and P.J. Sterk ${ }^{\#}$}

*Pulmonary and Critical Care Medicine, Christian Medical College and Hospital, Chandigarh Road, Ludhiana, India.

"Lung Function Lab, Leiden University Medical Center, Leiden, The Netherlands.

\section{REFERENCES}

1 Ambrosino N, Vagheggini G. Noninvasive positive pressure ventilation in the acute care setting: where are we? Eur Respir J 2008; 31: 874-886.

2 Tran TH, Nguyen TL, Nguyen TD, et al. Avian influenza A (H5N1) in 10 patients in Vietnam. N Engl J Med 2004; 350: 1179-1188.

3 Antonelli M, Conti G, Bufi M, et al. Noninvasive ventilation for treatment of acute respiratory failure in patients undergoing solid organ transplantation: a randomized trial. JAMA 2000; 283: 235-241.

4 Sadovnikoff N, Varon J. CPAP mask management of varicella-induced respiratory failure. Chest 1993; 103: 1894 1895.

5 Hui DS, Hall SD, Chan MTV et al. Noninvasive positivepressure ventilation: an experimental model to assess air and particle dispersion. Chest 2006; 130: 730-740.

6 World Health Organization. Infection prevention and control of epidemic- and pandemic-prone acute respiratory diseases in health care. WHO Interim Guidelines. World Health Organization, 2007. www.who.int/csr/resources/publications/ WHO_CD_EPR_2007_6/en/ Date last accessed: April 4, 2008. Last updated: June 2007. 